\title{
Intrathoracic phrenic pacing: A 10-year experience in France
}

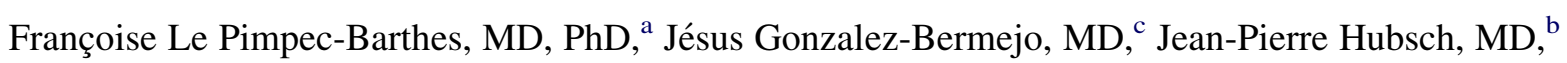 \\ Alexandre Duguet, $\mathrm{MD}, \mathrm{PhD},{ }^{\mathrm{c}}$ Capucine Morélot-Panzini, $\mathrm{MD},{ }^{\mathrm{c}}$ Marc Riquet, $\mathrm{MD}, \mathrm{PhD},{ }^{\mathrm{a}}$ and \\ Thomas Similowski, MD, $\mathrm{PhD}^{\mathrm{c}}$
}

\begin{abstract}
Background: Phrenic pacing is an alternative to positive-pressure ventilation in selected patients, mostly in cases of upper spinal cord injury. We evaluated results of phrenic pacing performed by video-assisted thoracic surgery (VATS).

Method: Between 1997 and 2007, after complete neuromuscular investigations, 20 patients requiring full-time ventilation were selected for phrenic pacing (19 with posttraumatic tetraplegia and 1 with congenital central hypoventilation syndrome). Quadripolar cuff electrodes were fixed around each intrathoracic phrenic nerve via bilateral VATS. They were connected to a subcutaneous radiofrequency receiver coupled to an external radiofrequency transmitter. All patients participated in a reconditioning program beginning 2 weeks after implantation and continued until ventilatory weaning.
\end{abstract}

Results: Phrenic pacing was successful in all cases. No intraoperative complications or perioperative mortality were observed. Intraoperative testing detected stimulation thresholds in 19 patients (range, 0.05-2.9 mA). Ventilatory weaning was obtained in 18 patients. Median diaphragm reconditioning time was 6 weeks ( 2 weeks-11 months). Reconditioning was still in process in a young woman and was not achieved in an elderly woman with a 4-year history of tetraplegia. All the patients weaned from mechanical ventilation reported improved quality of life. Failure or delay in recovery of effective diaphragm contraction was due to nonreversible amyotrophy.

Conclusions: VATS implantation of 4-pole electrodes around the intrathoracic phrenic nerve is a safe procedure. Ventilatory weaning correlates with the degree of diaphragmatic amyotrophy. Phrenic pacing, performed as soon as neurologic and orthopedic stabilization is achieved, is the most important prognostic factor for successful weaning. (J Thorac Cardiovasc Surg 2011;142:378-83)

Phrenic pacing is indicated to wean patients who are ventilator dependent because of central respiratory paralysis but who retain functional phrenic nerves and diaphragm. Upper cervical spinal cord injury above or at the $\mathrm{C} 3$ level and central alveolar hypoventilation (either congenital or acquired) are currently the 2 main indications for this technique. ${ }^{1,2}$ Compared with mechanical ventilation, phrenic pacing provides more natural breathing dynamics, reduces the

From The Department of Thoracic Surgery, ${ }^{\mathrm{a}}$ and the Department of Anesthesiology and Intensive Care, ${ }^{\mathrm{b}}$ Assistance Publique-Hôpitaux de Paris, Hôpital Européen Georges Pompidou, Paris Descartes University, Paris, France; and Department of Respiratory and Intensive Medicine Unit, ${ }^{\mathrm{c}}$ Assistance Publique-Hôpitaux de Paris, Groupe Hospitalier Pitié-Salpêtrière, Paris, France.

The study was supported by grant DRC 98075 from the Programme Hospitalier de Recherche Clinique National of the French Ministry of Heatlh (PHRC) and by association ADOREP, Paris, France. The diaphragm pacing activity of the Service de Pneumologie et Réanimation, Groupe Hospitalier Pitié-Salpêtrière, Paris, France, is supported in part by association ADEP, Puteaux, France and by association CARDIF, Fontenay-aux-Roses, France.

Disclosures: T. Similowski received honoraria from Atrotech Ltd for the translation from English to French of the user's manual of the Atrostim device used in the patients described in this article, in 2002. There are no other conflicts of interest involved.

Received for publication Nov 11, 2010; revisions received March 3, 2011; accepted for publication April 26, 2011; available ahead of print May 27, 2011.

Address for reprints: Françoise Le Pimpec-Barthes, MD, PhD, Department of Thoracic Surgery, Georges Pompidou European Hospital, 20 rue Leblanc 75908. Paris Cedex 15, France (E-mail: francoise.lepimpec-barthes@egp.aphp.fr). $0022-5223 / \$ 36.00$

Copyright (C) 2011 by The American Association for Thoracic Surgery doi: $10.1016 /$ j.jtcvs.2011.04.033 occurrence of respiratory infection, ${ }^{3}$ and improves quality of life, ${ }^{4}$ in part through restored olfaction. ${ }^{4}$ It is also considered to allow reductions in health care costs, driven by easier discharge to home and the reduction in infections. ${ }^{3,5}$ The limited number of patients eligible for the technique explains why most published series are small, ${ }^{3}$ with the exception of the comparative work published by Hirschfeld and associates. ${ }^{3}$ Since 1997, a collaborative group including respiratory physicians, pediatricians, and thoracic surgeons has been implanting intrathoracic phrenic stimulators in France. Thanks to private funding (mostly from insurance companies) and to public grants, it has been possible to constitute a relatively large (28 patients) cohort. The purpose of this article is to share with the community the results that we obtained in the first 20 patients of this cohort who achieved a 36-month follow-up. This duration was arbitrarily chosen to define a homogeneous convenience sample of patients in reasonably stable condition.

\section{PATIENTS AND METHODS}

\section{Patient Population and Methods of Selection}

With external approval by the appropriate French body and the consent of the patients, data were obtained in 20 consecutive patients receiving intrathoracic phrenic stimulators between December 1997 and May 2007 among a total of 28 (Figure 1). There were 14 male and 6 female patients aged 7 to 57 years (mean age, 27.1 years) requiring full-time ventilatory support because of high cervical spinal injuries above or at C3 level $(\mathrm{n}=18)$, complication of brainstem neurosurgery $(\mathrm{n}=1$, patient 20 in 


\section{Abbreviations and Acronyms \\ $\mathrm{EMG}=$ electromyographic \\ VATS $=$ video-assisted thoracic surgery}

Table 1), and congenital central hypoventilation syndrome ( $\mathrm{n}=1$, patient 3 in Table 1). The causes of the traumatic spinal lesions were as follows: motor vehicle or motorcycle accident, $\mathrm{n}=12$; diving accident, $\mathrm{n}=1$; horseback riding accident, $\mathrm{n}=1$; kite surfing accident, $\mathrm{n}=1$; rugby scrumming accident, $\mathrm{n}=1$; and bicycle accident, $\mathrm{n}=1$.

Inclusion criteria. Beyond ventilator dependency, the indication for phrenic pacing was retained in the following circumstances:

1. Diagnostic phrenic nerve stimulation, under the form of cervical magnetic stimulation ${ }^{6}$ and/or of electrical stimulation of the phrenic nerve in the neck, showed the presence of an electromyographic (EMG) response of the diaphragm attesting to the integrity of the phrenic nerve. $^{7,8}$

2. Transcranial magnetic stimulation showed the full interruption of the corticospinal phrenic pathway, attested to by the complete lack of EMG response and making future recovery unlikely ${ }^{7,8}$; this criterion was requested in the tetraplegic patients only.

Exclusion criteria. Exclusion criteria were an abolished response of the diaphragm to cervical magnetic stimulation, gas exchange abnormalities, any significant comorbidity, psychiatric disorders, or complete social isolation.

\section{Device}

The device was a quadripolar phrenic pacing system from Atrotech (Jukka, Atrotech; Tampere, Finland) that had 2 components: internal (the permanently implanted device) and external antenna taped to the skin and connected to the transmitter) (Figure 2). The internal component consisted of quadripolar electrodes (each measuring $2 \mathrm{~mm}$ ) in a cuff configuration (Figure 3), 1 for each phrenic nerve, connected by wires to subcutaneous radiofrequency receivers (Figure 4). Each electrode was opposed to a quarter of the nerve to subsequently stimulate the nerve fibers of that portion and each portion was stimulated during a quarter of the time, allowing the 3 other portions to rest.

The external component consisted of external antennas taped over the subcutaneous receivers and connected to a radiofrequency transmitter (Figure 2) providing stimulation of the phrenic nerve according to preestablished parameters (frequency, intensity).

\section{Implantation Technique}

Video-assisted thoracic surgery (VATS) was used in all the patients. A 4$\mathrm{cm}$ incision was made in the second intercostal space, $3 \mathrm{~cm}$ lateral to the sternum. The endoscopic camera was inserted into the pleural space laterally through another port located in the third intercostal space. Careful dissection of the phrenic nerve was carried out in front of the vena cava on the right and in the pulmonary hilum on the left. These levels of implantation are seen on the chest X-ray film (Figure 5). Quadripolar electrodes were implanted on each side, 2 above and 2 below the nerve (Figure 3). Each Teflon patch was sutured on the surrounding tissue (pleura or pericardium) to prevent any displacement. Wires from the electrodes were sutured on the pericardium, brought out through the anterior minithoracotomy, and tunneled under the pectoralis major muscle to a subcutaneous pocket located in the lower chest wall. The wires were then connected to the subcutaneous radiofrequency receivers on each side (Figure 4). Intraoperative testing of each electrode validated correct positioning and determined the minimum stimulation thresholds to be used to begin diaphragmatic recondition-

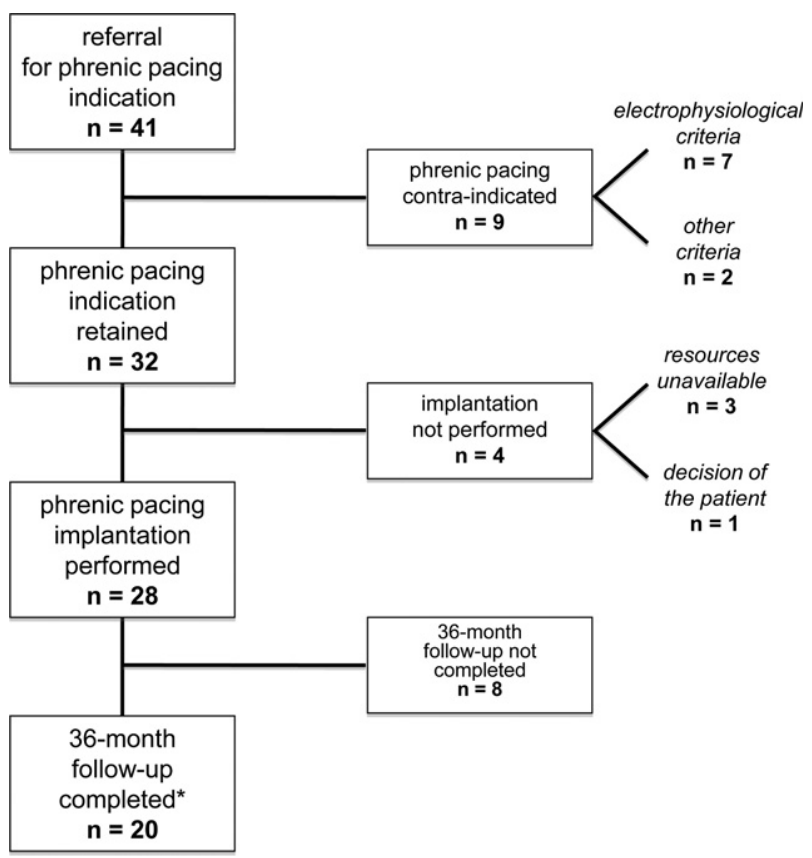

FIGURE 1. Flow chart of the patients referred for phrenic pacing at our center over the period of interest for possible phrenic pacing. * Or death before 36 months.

ing. A chest drain was inserted in each pleural space exiting through the thoracoscopic lateral port.

\section{Diaphragm Reconditioning}

Diaphragm reconditioning began 2 weeks after the surgical procedure. Stimulation sessions were performed on a daily basis. Their duration was determined according to a breath-by-breath monitoring of tidal volume that had to remain above $50 \%$ of its value as determined during the second minute spent off the ventilator with the stimulator on. Initial sessions could be as short as 2 minutes. Intervals of 24 hours between sessions were initially allowed to permit the recovery of diaphragm fatigue and to minimize the risk owing to excessive loading. ${ }^{9}$ The intersession interval was reduced as soon as fused contractions were observed. ${ }^{10}$ In 1 patient, initial diaphragm stimulation did not produce a tidal volume compatible with gas exchange. The reconditioning procedure was therefore initiated on top of the patient's ventilatory assistance. The reconditioning procedure was considered complete when the patients could spend 8 hours under stimulation without any significant drop in tidal volume (eighth hour value above $90 \%$ of the initial value).

\section{Subsequent Follow-up}

The patients were hospitalized for a systematic follow-up 6 months after implantation, then once a year for a few years, and then once every 2 years or more. During each of these 2-day stays, the stimulation thresholds were verified, the ventilation produced by stimulation was measured, and room air blood gases under stimulation and under ventilation were performed. If necessary, stimulation thresholds were adjusted, and ventilation and stimulation settings were adapted to produce comparable levels of ventilation

Open interviews regarding daily activities and quality of life were conducted. During these interviews, the patients were asked to "talk about their perception of life before and after stimulation," in their own words. After having expressed themselves, they were asked by the investigators 
TABLE 1. Time to implantation, surgical stimulation results, and duration of reconditioning in the study population

\begin{tabular}{|c|c|c|c|}
\hline $\begin{array}{c}\text { Patient } \\
\text { no. } \\
\end{array}$ & $\begin{array}{c}\text { Time to } \\
\text { implantation }(\mathrm{mo})\end{array}$ & $\begin{array}{l}\text { Mean threshold } \\
\text { for electrodes } \\
\text { on each side } \\
\text { (left/right) }(\mathbf{m A})\end{array}$ & $\begin{array}{c}\text { Reconditioning } \\
(\mathbf{w k})\end{array}$ \\
\hline 1 & 18 & $0.5 / 1.1$ & 8 \\
\hline 2 & 10 & $1.7 / 1.7$ & 4 \\
\hline 3 & - & $1 / 1$ & 12 \\
\hline 4 & 12 & $0.4 / 0.1$ & 4 \\
\hline 5 & 19 & $0.1 / 0.6$ & 4 \\
\hline 6 & 48 & ND & Failure \\
\hline 7 & 12 & $1.7 / 1.4$ & 4 \\
\hline 8 & 21 & $1 / 1$ & 4 \\
\hline 9 & 86 & $1.1 / 1.2$ & 12 \\
\hline 10 & 64 & $0.6 / 0.6$ & 44 \\
\hline 11 & 33 & $0.9 / 0.7$ & 12 \\
\hline 12 & 19 & $0.7 / 0.4$ & 12 \\
\hline 13 & 17 & $1.4 / 1.4$ & 2 \\
\hline 14 & 6 & $1 / 0.8$ & 8 \\
\hline 15 & 7 & $0.8 / 0.7$ & 6 \\
\hline 16 & 54 & $1.4 / 2.2$ & Incomplete \\
\hline 17 & 41 & $1.1 / 0.9$ & 6 \\
\hline 18 & 9 & $1.1 / 0.8$ & 4 \\
\hline 19 & 8 & $1.1 / 2.1$ & 16 \\
\hline 20 & 11 & $1.4 / 0.7$ & 4 \\
\hline
\end{tabular}

whether or not the considered that overall phrenic stimulation had improved their self-perceived condition. In addition, some of them were exposed to a validated questionnaire (the "satisfaction with life scale") and a formal in-house questionnaire. ${ }^{4}$

The number of tracheal suctions performed daily was recorded. The patients and caregivers were asked about suspected episodes of respiratory infections, a diagnosis that was retained in the presence of 3 or more of the following: fever, increased need for tracheal suction, decreased performance of the stimulator, and prescription of antibiotics.

\section{RESULTS}

\section{Preoperative Assessment}

Diagnostic phrenic nerve stimulation showed a bilateral EMG response of the diaphragm in all cases (surface EMG recordings). The latency of this response was within the normal range (between 5.5 and $6.5 \mathrm{~ms}$ for cervical mag-

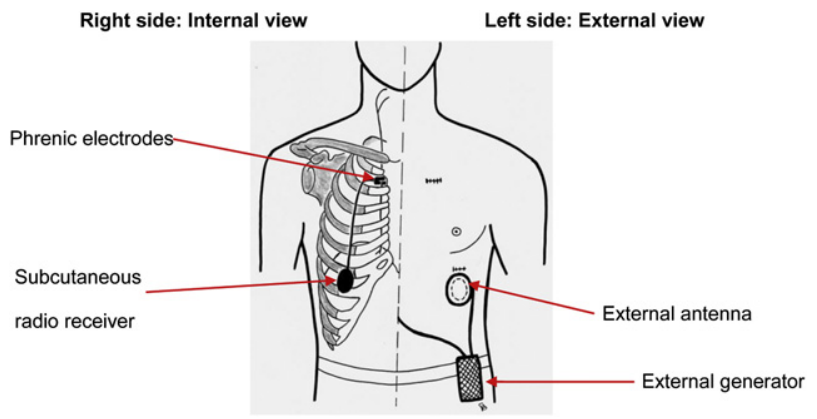

FIGURE 2. General view of the intrathoracic phrenic pacing device.

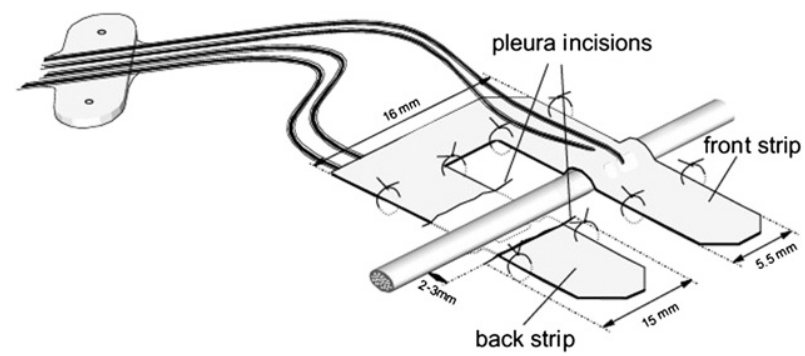

FIGURE 3. Schematic representation of the electrodes positioned around the phrenic nerve. Four platinum contacts are positioned around the nerve so as to stimulate roughly a quarter of the phrenic fibers during sequential stimulation.

netic stimulation and between 6.5 and $8 \mathrm{~ms}$ for electrical stimulation) ${ }^{11}$ in all cases but 2 , in which moderately slow responses were observed.

In the tetraplegic patients, transcranial magnetic stimulation never elicited any diaphragmatic response, in line with a full and nonreversible interruption of central respiratory pathways.

In the patient with congenital central alveolar hypoventilation, transcranial magnetic stimulation did elicit a normal response, with a normal latency on both sides $(18 \mathrm{~ms}$ and $17.5 \mathrm{~ms}$ on the right and left side, respectively). ${ }^{12}$

In 19 of the patients, the EMG response of the diaphragm had a clear mechanical counterpart, attested to by the production of a negative intrathoracic pressure (as measured at the tracheal cannula; $4.3 \pm 3.2 \mathrm{~cm} \mathrm{H}_{2} \mathrm{O}, 0.5-8 \mathrm{~cm}$ $\mathrm{H}_{2} \mathrm{O}$ ), concomitant with an increase in abdominal circumference attesting to the actual presence of a diaphragm contraction.

In 1 patient (a woman, patient 6 in Table 1), there was a small EMG response of the diaphragm to phrenic stimulation but no clear mechanical counterpart. Intradiaphragmatic recordings of the diaphragm using needle electrodes

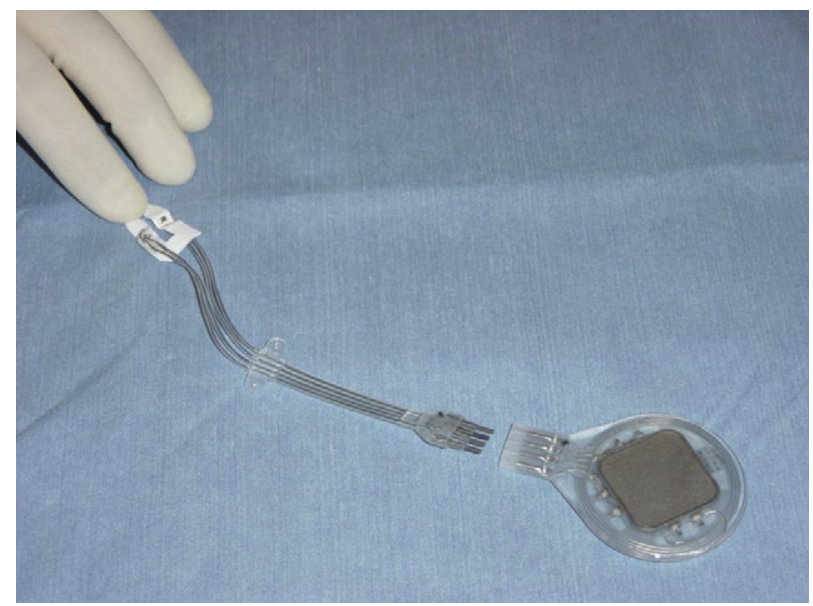

FIGURE 4. The quadripolar electrodes mounted on their Teflon patch (left) connected to the subcutaneous receiver (right). 


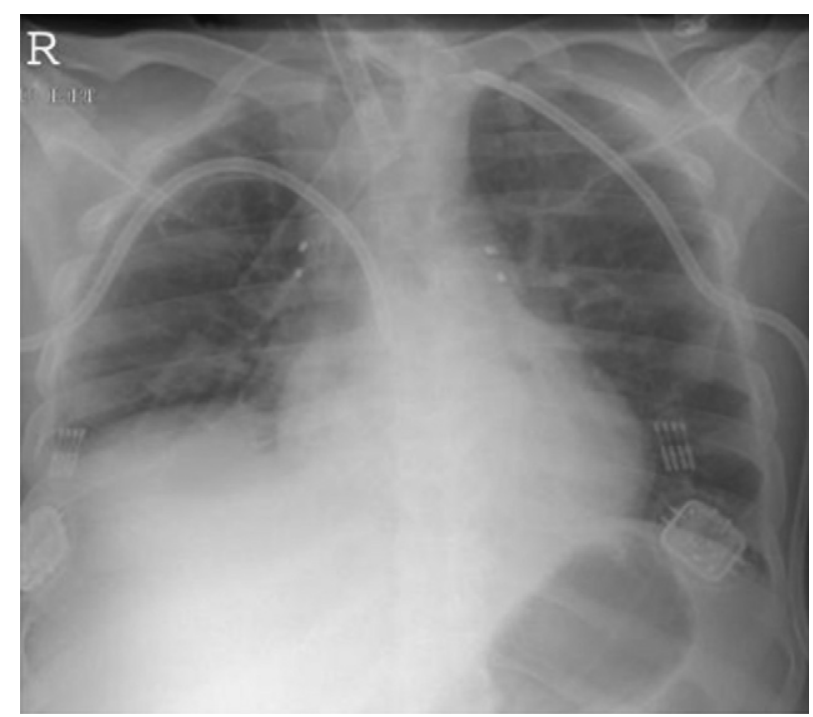

FIGURE 5. Example of a chest $x$-ray film taken in 1 patient to show the location of the electrodes. In the right cavity, the electrode is placed on the phrenic nerve at the level of the vena cava. In the left cavity, the electrode is placed on the phrenic nerve at the level of the aorta root.

confirmed, in this patient, that the surface EMG response did indeed correspond to a diaphragmatic contraction, hence the decision to proceed with the implantation.

\section{Early Postoperative Period}

No significant intraoperative complications were observed. Identifying the phrenic nerve and dissecting it proved straightforward in all cases. No nerve injury occurred, as attested to by a consistent response of the diaphragm to intraoperative test stimulations.

Intraoperative testing showed homogeneous stimulation thresholds for the 4 components of the quadripolar electrodes in 19 patients, ranging from 0.05 to $2.9 \mathrm{~mA}$ (mean threshold for electrodes on each side are given in Table 1). No visible diaphragm contractions were obtained in the patient whose preoperative testing had failed to evidence a mechanical response of the diaphragm to phrenic stimulation (patient 6 in Table 1).

There was no early postoperative mortality or major morbidity. There were, however, 2 cases of pneumonia with partial atelectasis that regressed with bronchial aspiration and intravenous antibiotic therapy.

Chest tubes were removed a few hours $(n=4)$ or the day after surgery $(\mathrm{n}=16)$ with no residual pneumothorax, reintervention, or pleural redrainage.

All the patients were discharged from the surgery department after 2 postoperative days.

\section{Thirty-Six Months' Follow-up}

Complete reconditioning (see above) was obtained in 18 of the 20 patients. This was achieved before 2 months in 13 patients (including 3 in less than 4 weeks), from 2 to 3 months in 3 patients, and in more than 3 months in 2 patients (Table 1). The characteristics of the patients were similar in the 3 categories of weaning duration.

Physiologically, all these patients subsequently proved able to withstand stimulation 24 hours a day. Nevertheless, 8 of them (out of 18) refused to renounce nocturnal mechanical ventilation. This choice was always driven by anxiety, the patients being deterred from nocturnal pacing by the absence of the "efficiency alarm" they were used to with mechanical ventilation (phrenic stimulators have only "electronic failure" alarms and do not monitor ventilation).

One complete weaning failure was observed in the oldest woman (patient 6 in Table 1), who exhibited profound diaphragmatic amyotrophy during the preoperative testing.

One patient recovered only partial ventilatory autonomy (patient 16 in Table 1) and eventually gave up stimulation attempts. This patient had severe malnutrition that failed to be corrected by aggressive enteral and parenteral management.

All the patients who could be weaned from mechanical ventilation $(n=18)$ reported improved comfort and quality of life. According to open interviews, weaning facilitated mobilization in the house and outside, as well as nursing care. It was also said to improve the senses of smell and taste, the ability to eat and drink, and generally made speaking easier. The patients who chose to sleep under phrenic stimulation consistently reported a better quality of sleep, mainly owing to the absence of ventilator-related noise. The patients were unanimous in reporting that phrenic stimulation had made their return home easier.

The median number of suspected episodes of respiratory infections per year was 0.653 during the preimplantation period (interquartile range, 0.04-1.73) and 0.139 after implantation (interquartile range, 0.01-0.22). The median number of daily tracheal suctions was 5.2 before implantation (interquartile range, 1.9-7.2) and 3.0 after implantation (0.2-4).

Seven of the 18 patients who had been weaned from their ventilator died 6 to 74 months after implantation. Causes of death included septic shock of extrapulmonary origin $(\mathrm{n}=2)$, digestive hemorrhage $(\mathrm{n}=1)$, pneumonia $(\mathrm{n}=2)$, intracerebral hemorrhage $(\mathrm{n}=1)$, and intracerebral abscess $(\mathrm{n}=1)$. No deaths were directly attributable to phrenic stimulation.

\section{DISCUSSION}

This report mainly shows that the French experience with intrathoracic phrenic pacing is similar to the worldwide experience, as described by various publications ${ }^{3,13-15}$ since the introduction of the technique in clinical practice. ${ }^{16,17}$ The main weakness of this study is the absence of a control group. However, the size and the homogeneity of the cohort that we describe put this experience among large ones and make it worth sharing. 


\section{Patient Selection}

In comparison with other studies, we used stringent electrophysiologic criteria to select the candidates for phrenic pacing. In particular, we used transcranial magnetic stimulation to ascertain that the patients in whom we implanted the quadripolar phrenic pacing system were unlikely to exhibit late recovery of a spontaneous recovery activity. ${ }^{8,18}$ This was mostly done because the technique was at the time not normally available through the French health care system, which implied a very careful resources allocation process. Otherwise, it is conceivable to retain the indication of phrenic pacing in patients with central respiratory paralysis and functional phrenic nerves whatever the response to transcranial magnetic stimulation, even if this means that some patients will eventually stop being paced if they do subsequently recover.

Of note, the delay elapsed since the injury does not seem to be a major determinant of the reconditioning dynamics. Even though the longest reconditioning durations were observed in patients with rather ancient trauma, patients 9 and 12 (Table 1) had the same reconditioning time (12 weeks) with posttraumatic delays of 86 and 19 months, respectively. In the study by Onders, Elmo, and Ignagni, ${ }^{19}$ successful weaning was achieved in patients who had been quadriplegic up to 19 years. We therefore believe that the delay since the lesion should probably not be a selection criterion in itself.

\section{Surgical Technique and Postoperative Complications}

The VATS intrathoracic approach that we used is simple and safe for thoracic surgeons. It is minimally invasive, even in case of partial pleural symphysis, and can be used for lung resections. ${ }^{20}$ We did not observe any peroperative complication, and in particular we never observed surgery-induced phrenic nerve dysfunction. Of note, the complete thoracoscopic placement of bipolar electrodes has been reported in 9 children, ${ }^{21}$ with a rather high morbidity rate of $44 \%$ (trocar insertion in the liver, postoperative pneumothorax, and atelectasis). Of note also, an endoscopic approach with robotic assistance has been used in 6 adult patients, ${ }^{22}$ without complications. Delayed postoperative dysfunction of phrenic stimulators has been described, at times requiring reintervention. ${ }^{14,23}$ Thus, in the series of 22 patients described by Garrido-Garcia and colleagues, ${ }^{14} 5$ patients needed reintervention for infection and phrenic nerve entrapment. We did not encounter such a situation. All in all, our experience adds to the safety $\log$ of the technique. This is particularly reassuring with respect to a concern that is often voiced by patients with central congenital alveolar hypoventilation. These patients have central respiratory paralysis during sleep only and have no motor handicap. When an indication for phrenic pacing is discussed, they are often anxious about the possibility of phrenic nerve damage. We, however, acknowledge that this is a single operator series, which probably optimizes safety.

In the past, phrenic pacing through cervically implanted electrodes has been used. ${ }^{16,17}$ The noninvasiveness of this approach is interesting, but electrode damage has been reported owing to neck mobility. In addition, the phrenic nerve is often incomplete at the base of the neck (accessory phrenic nerve from $\mathrm{C} 5$ meeting the $\mathrm{C} 4$ contingent behind the clavicle). The laparoscopic approach for phrenic pacing that has been recently introduced ${ }^{1,24}$ is theoretically interesting because of its relatively low technology and simplified operative and postoperative times that should make it more cost effective. In the absence of comparative studies, it is however not currently possible to define criteria to choose one technique or the other when an indication is retained.

\section{Reconditioning}

We conducted diaphragm reconditioning according to previously published information, ${ }^{10}$ without encountering particular difficulties. Two particular observations seem worthy of notice. First, the only patient in our series who fully failed to be reconditioned and did not recover any ventilatory autonomy was the only one who had marked malnutrition. This could have played a role in the conditioning failure, and we submit that a poor nutritional status must demand caution in evaluating the indication of phrenic pacing. The interest of nutritional support in such cases would have to be evaluated. Second, in 1 patient postoperative phrenic stimulation could not produce enough ventilation for the standard reconditioning protocol to be used. Performing stimulation sessions during mechanical ventilation proved an efficient way to obtain the minimal degree of reconditioning necessary to go forward. This approach has seemingly not been described before and seems worth keeping in mind.

\section{Patient-Related Outcomes}

As in other reports, our patients generally gave very positive opinions of phrenic pacing. However, this result must be taken with caution. Indeed, the "open interview" approach that we relied on and the absence of a control group are major sources of bias. This is particularly true because tetraplegic ventilator-dependent patients place great hopes in any intervention likely to change their condition. Nevertheless, the results were the same in the subpopulation in which formal questionnaires were used. ${ }^{4}$ Of importance, the recovery of smell ${ }^{4}$ corresponds to an objective physiologic benefit that is strongly associated by the patients with something pleasurable. As in other reports, ${ }^{14}$ our patients tended to associate phrenic pacing with the possibility to return home and to be somewhat socially reinserted. Several of them, who had been supported by mechanical ventilation for some time and had not been able to resume 
significant social interactions, could do so after phrenic pacing ( 1 patient assumed accounting responsibilities in his firm and participated in sales; 1 patient, an enologist, resumed wine tasting after phrenic pacing; and 1 patient completed his high school studies that he had not been able to continue with mechanical ventilation).

In line with the observations of Hirschfeld and colleagues, ${ }^{3}$ we observed a tendency for episodes of suspected respiratory infections to become rarer in outpatients. The reduced need for tracheal suctions that we observed was much appreciated by the patients and their caregivers.

Of note, tracheostomy removal was not proposed to our patients. This was driven by safety considerations (ease of reventilation in the event of an acute problem; risk of obstructive apneas owing to the lack of upper airway dilators-diaphragm synchronization). In other experiences, patients with phrenic nerve pacing have successfully had their tracheostomy removed. We acknowledge that our attitude may correspond to some amount of "safety overkill," but it did not prevent benefits. Future studies are needed to determine the actual best management of this issue. Of note, the maintenance of a tracheostomy should not have a major impact on the cost-effectiveness of the technique, which is mostly driven by home discharge and infections. ${ }^{3,5}$

In conclusion, our experience with intrathoracic phrenic pacing confirms that this technique is efficient in liberating ventilator-dependent patients with central respiratory paralysis from the ventilator. The VATS approach to implant the electrodes on the phrenic nerves is safe and minimally traumatic. Patients report deriving subjective and objective benefits from the technique. As a result, the French experience with intrathoracic phrenic pacing fuels the notion that this method of care can be useful and should, in the future, be evaluated in the context of standard care.

\section{ADDENDUM}

Prior publications: None. Data gathered in some of the patients constituting the present cohort have been used in 2 publications:

Adler D, Gonzalez-Bermejo J, Duguet A, Demoule A, Le Pimpec-Barthes F, Hurbault, A, et al. Diaphragm pacing restores olfaction in tetraplegia. Eur Respir J. 2009;34:365-70.

Le Pimpec-Barthes F, Brian E, Vlas C, GonzalezBermejo J, Bagan P, Badia A, et al. Le traitement chirurgical des éventrations et paralysies, diaphragmatiques [surgical treatment of diaphragmatic eventration and paralysis]. Rev Mal Respir. 2010;27:565-78.

We are grateful to Pasi Talonen and Serge Renaux for technical help during the intervention and their general support. We are also grateful to Marilyn Amouyal-Jones and Valerie Mège-Lin for their help with English style and grammar.

\section{References}

1. DiMarco AF. Phrenic nerve stimulation in patients with spinal cord injury. Respir Physiol Neurobiol. 2009;169:200-9.

2. Weese-Mayer DE, Berry-Kravis EM, Ceccherini I, Keens TG, Loghmanee DA, Trang H. An official ats clinical policy statement: congenital central hypoventilation syndrome: genetic basis, diagnosis, and management. Am J Respir Crit Care Med. 2010;181:626-44.

3. Hirschfeld S, Exner G, Luukkaala T, Baer GA. Mechanical ventilation or phrenic nerve stimulation for treatment of spinal cord injury-induced respiratory insufficiency. Spinal Cord. 2008;46:738-42.

4. Adler D, Gonzalez-Bermejo J, Duguet A, Demoule A, Le Pimpec-Barthes F, Hurbault A, et al. Diaphragm pacing restores olfaction in tetraplegia. Eur Respir J. 2009;34:365-70.

5. Esclarín A, Bravo P, Arroyo O, Mazaira J, Garrido H, Alcaraz MA. Tracheostomy ventilation versus diaphragmatic pacemaker ventilation in high spinal cord injury. Paraplegia. 1994;32:687-93.

6. Similowski T, Fleury B, Launois S, Cathala HP, Bouche P, Derenne JP. Cervical magnetic stimulation: a new painless method for bilateral phrenic nerve stimulation in conscious humans. J Appl Physiol. 1989;67:1311-8.

7. Similowski T, Straus C, Attali V, Duguet A, Jourdain B, Derenne JP. Assessment of the motor pathway to the diaphragm using cortical and cervical magnetic stimulation in the decision-making process of phrenic pacing. Chest. 1996;110: 1551-7.

8. Duguet A, Demoule A, Gonzalez J, Remy-Neris O, Derenne JP, Similowski T Predicting the recovery of ventilatory activity in central respiratory paralysis. Neurology. 2006;67:288-92.

9. Zhu E, Petrof BJ, Gea J, Comtois N, Grassino AE. Diaphragm muscle fiber injury after inspiratory resistive breathing. Am J Respir Crit Care Med. 1997;155: 1110-6.

10. Nochomovitz ML, Hopkins M, Brodkey J, Montenegro H, Mortimer JT, Cherniack NS. Conditioning of the diaphragm with phrenic nerve stimulation after prolonged disuse. Am Rev Respir Dis. 1984;130:685-8.

11. American Thoracic Society, European Respiratory Society. Ats/ers statement on respiratory muscle testing. Am J Respir Crit Care Med. 2002;166:518-624.

12. Similowski T, Straus C, Coic L, Derenne JP. Facilitation-independent response of the diaphragm to cortical magnetic stimulation. Am J Respir Crit Care Med. 1996;154:1771-7.

13. Fodstad H, Blom S. Phrenic nerve stimulation (diaphragm pacing) in chronic singultus. Neurochirurgia. 1984;27:115-6.

14. Garrido-Garcia H, Mazaira Alvarez J, Martin Escribano P, Romero Ganuza J, La Banda F, Gambarrutta C, et al. Treatment of chronic ventilatory failure using a diaphragmatic pacemaker. Spinal Cord. 1998;36:310-4

15. Khong P, Lazzaro A, Mobbs R. Phrenic nerve stimulation: the Australian experience. J Clin Neurosci. 2010;17:205-8.

16. Van Heeckeren DW, Glenn WW. Electrophrenic respiration by radiofrequency induction. J Thorac Cardiovasc Surg. 1966;52:655-65.

17. Glenn WW, Holcomb WG, McLaughlin AJ, O'Hare JM, Hogan JF, Yasuda R. Total ventilatory support in a quadriplegic patient with radiofrequency electrophrenic respiration. Proc Veterans Adm Spinal Cord Inj Conf. 1971;18:81-6.

18. Oo T, Watt JW, Soni BM, Sett PK. Delayed diaphragm recovery in 12 patients after high cervical spinal cord injury. A retrospective review of the diaphragm status of 107 patients ventilated after acute spinal cord injury. Spinal Cord. 1999;37:117-22.

19. Onders RP, Elmo MJ, Ignagni AR. Diaphragm pacing stimulation system for tetraplegia in individuals injured during childhood or adolescence. J Spinal Cord Med. 2007;30(Suppl. 1):S25-9.

20. Flores RM, Alam N. Video-assited thoracic surgery lobectomy (VATS), open thoracotomy, and the robot for lung cancer. Ann Thorac Surg. 2008;85:S710-5.

21. Shaul DB, Danielson PD, McComb JG, Keens TG. Thoracoscopic placement of phrenic nerve electrodes for diaphragmatic pacing in children. J Pediatr Surg. 2002;37:974-8; discussion 974-8.

22. Morgan JA, Morales DL, John R, Ginsburg ME, Kherani AR, Vigilance DW, et al. Endoscopic, robotically assisted implantation of phrenic pacemakers. $J$ Thorac Cardiovasc Surg. 2003;126:582-3.

23. Weese-Mayer DE, Silvestri JM, Kenny AS, Ilbawi MN, Hauptman SA Lipton JW, et al. Diaphragm pacing with a quadripolar phrenic nerve electrode: an international study. Pacing Clin Electrophysiol. 1996;19:1311-9.

24. Onders RP, Elmo M, Khansarinia S, Bowman B, Yee J, Road J, et al. Complete worldwide operative experience in laparoscopic diaphragm pacing: results and differences in spinal cord injured patients and amyotrophic lateral sclerosis patients. Surg Endosc. 2009;23:1433-40. 